AIR WAR COLLEGE

AIR UNIVERSITY

\title{
A CODE OF ETHICS AND PROFESSIONAL CONDUCT FOR NSA INTELLIGENCE PROFESSIONALS
}

\author{
By \\ Katherine A. Anderson/GS15, Civilian \\ A Research Report Submitted to the Faculty \\ In Partial Fulfillment of the Graduation Requirements \\ Advisor: Dr. Kimberly Hudson
}

17 February 2015 


\section{Report Documentation Page}

Form Approved

OMB No. 0704-0188

Public reporting burden for the collection of information is estimated to average 1 hour per response, including the time for reviewing instructions, searching existing data sources, gathering and maintaining the data needed, and completing and reviewing the collection of information. Send comments regarding this burden estimate or any other aspect of this collection of information,

including suggestions for reducing this burden, to Washington Headquarters Services, Directorate for Information Operations and Reports, 1215 Jefferson Davis Highway, Suite 1204, Arlington

VA 22202-4302. Respondents should be aware that notwithstanding any other provision of law, no person shall be subject to a penalty for failing to comply with a collection of information if it

does not display a currently valid OMB control number.

\begin{tabular}{|c|c|c|}
\hline $\begin{array}{l}\text { 1. REPORT DATE } \\
\mathbf{1 7} \text { FEB } 2015\end{array}$ & 2. REPORT TYPE & $\begin{array}{l}\text { 3. DATES COVERED } \\
\mathbf{0 0 - 0 0 - 2 0 1 5} \text { to 00-00-2015 }\end{array}$ \\
\hline \multirow{3}{*}{\multicolumn{2}{|c|}{$\begin{array}{l}\text { A Code Of Ethics And Professional Conduct For NSA Intelligence } \\
\text { Professionals }\end{array}$}} & 5a. CONTRACT NUMBER \\
\hline & & 5b. GRANT NUMBER \\
\hline & & 5c. PROGRAM ELEMENT NUMBER \\
\hline \multirow{3}{*}{\multicolumn{2}{|c|}{ 6. AUTHOR(S) }} & 5d. PROJECT NUMBER \\
\hline & & 5e. TASK NUMBER \\
\hline & & 5f. WORK UNIT NUMBER \\
\hline \multicolumn{2}{|c|}{$\begin{array}{l}\text { 7. PERFORMING ORGANIZATION NAME(S) AND ADDRESS(ES) } \\
\text { Air War College,,Air University,,Maxwell AFB,AL }\end{array}$} & $\begin{array}{l}\text { 8. PERFORMING ORGANIZATION } \\
\text { REPORT NUMBER }\end{array}$ \\
\hline \multirow{2}{*}{\multicolumn{2}{|c|}{ 9. SPONSORING/MONITORING AGENCY NAME(S) AND ADDRESS(ES) }} & 10. SPONSOR/MONITOR'S ACRONYM(S) \\
\hline & & $\begin{array}{l}\text { 11. SPONSOR/MONITOR'S REPORT } \\
\text { NUMBER(S) }\end{array}$ \\
\hline
\end{tabular}

12. DISTRIBUTION/AVAILABILITY STATEMENT

Approved for public release; distribution unlimited

13. SUPPLEMENTARY NOTES

14. ABSTRACT

The National Security Agency, established in 1952 by President Truman, has continued its cryptologic heritage in both the Signals Intelligence and Information Assurance missions. These missions entail collecting foreign intelligence for U.S. Government decision makers, from the President to senior civilian and military leaders. NSA???s SIGINT information is used to protect the U.S. military and allies, to fight terrorism, and to support diplomacy. Its Information Assurance mission protects national security information and ensures that government leaders receive this information securely and reliably.

15. SUBJECT TERMS

16. SECURITY CLASSIFICATION OF:

a. REPORT

unclassified b. ABSTRACT unclassified c. THIS PAGE unclassified
17. LIMITATION OF ABSTRACT

Same as Report (SAR)
18. NUMBER

OF PAGES

34 19a. NAME OF

RESPONSIBLE PERSON 


\section{DISCLAIMER}

The views expressed in this academic research paper are those of the author and do not reflect the official policy or position of the US government, the Department of Defense, or Air University. In accordance with Air Force Instruction 51-303, it is not copyrighted, but is the property of the United States government. 


\section{Biography}

Katherine A. Anderson, GS15 civilian, is assigned to the Air War College, Air University, Maxwell AFB, AL. She has served in a variety of engineering and management positions in a 17 year career in the U.S. Department of Defense. She managed technical and operational organizations and oversaw requirements and prioritization for a joint, technologybased portfolio for 4 U.S. Government Agencies. Ms. Anderson earned a B.S. Physics, with honors, and a M.S. Electrical Engineering. She is a certified Professional Project Manager. 


\begin{abstract}
The National Security Agency, established in 1952 by President Truman, has continued its cryptologic heritage in both the Signals Intelligence and Information Assurance missions. These missions entail collecting foreign intelligence for U.S. Government decision makers, from the President to senior civilian and military leaders. NSA's SIGINT information is used to protect the U.S. military and allies, to fight terrorism, and to support diplomacy. Its Information Assurance mission protects national security information and ensures that government leaders receive this information securely and reliably.
\end{abstract}

After the September 11, 2001 attacks, NSA, as well as the U.S. Intelligence Community, Military and other Government Agencies, were called upon to prevent future terrorist attacks. The ensuing Global War on Terror required increased intelligence gathering. Throughout its history, NSA has periodically weathered public criticism. Recent releases of volumes of classified information has caused ongoing criticism and examination despite having inflicted grave damage to U.S. National security. Moreover, recent public debates, while a necessary, integral part of our American democratic society, put untold stress on NSA employees, who traditionally, necessarily work in silence.

The intent of this paper is to urge NSA leaders to use new positive mechanisms, in addition to established legal and punitive means, to strengthen employee accountability and trust as releases of classified information continue and once-secret tools and techniques are examined publicly. This paper proposes that NSA establish a Code of Ethics and Professional Conduct to strengthen team cohesion and help employees resolve dilemmas about mission. It argues that articulating a Code of expected and aspirational behaviors will improve workforce resilience and thus protect against possible future releases of classified information. 
The paper describes shared values in the U.S. military Services and the Intelligence Community and proposes that NSA more explicitly define its values. It proposes updated NSA values and ties them to professional ethics while describing the benefits of articulating organizational values. By defining Intelligence as a profession, compared and contrasted with those of medicine and law, the author submits that defining the Intelligence profession will bolster employees' view of their work. Two recommendations are intended to provide first steps toward implementing this new employee focus. The first recommendation, a proposed NSA Code of Ethics and Professional Conduct, will enable employees to express their commitment to shared values. The second recommendation outlines a communication plan to enable all levels of NSA leadership to inculcate this Code throughout the workforce. NSA, by explicitly defining shared values and behavior expectations, will improve employee morale and cohesion. This will also reinforce commitments to lifelong obligations, and increase overseers and public confidence in the Agency's missions and compliance with law. 


\section{Introduction}

Intelligence Community insiders may release classified information for a variety of reasons, most of which are thwarted by monitoring, security investigations, and self-reporting. Recently, individuals responsible for extremely damaging releases of classified information have said that they were motivated by the belief that mission activities were wrong and/or that whistleblowing was morally required. Thwarting insider threats motivated by these feelings will require enabling insiders to address their conscience problems.

Responses to recent leaks and possible insider threats have spanned the United States Intelligence Community (IC), Federal Bureau of Investigation (FBI), and, most recently, the United States Congress. The Defense Authorization Act for FY2015 reportedly contains requirements for quarterly reports, for the next two years, about the Department of Defense's response to classified information leaks. The Act cites the fact that "hundreds of thousands of classified documents [that] were illegally copied and disclosed across the internet,” likely referring to the 2010 WikiLeaks disclosures by former U.S. soldier Manning ${ }^{1}$. It also refers to the classified information releases by Edward Snowden with the wording, "in 2013, nearly $1,700,000$ [classified] files were downloaded...the majority of the information compromised relates to the capabilities, operations, tactics, techniques, and procedures of the Armed Forces of the United States.” 2

Another highlight from the Defense Authorization Act of 2015 is that it requests "the adoption of an interim capability to continuously evaluate the security status of employees and contractors of the Department who have been granted...access to classified information.” ${ }^{3}$ Is this interim capability designed to detect problems of conscience? While consent to monitoring of U.S Government information systems is currently practiced in accordance with the 1981 
Executive Order $12333^{4}$, one wonders what type of additional monitoring will be entailed in ‘continuous evaluation of all security-cleared persons’ security status?

Security policies are designed to protect classified information and stop unauthorized disclosure of such information that can cause grave damage to the national security of the United States. However, Executive Order 12968, dated August 2, 1995, established uniform security policies to ensure fair and equal treatment for all Federal employees who access classified information. $^{5}$

While the concept of fairness is subjective, security-cleared employees are required to provide sensitive personal information in order to obtain and retain their jobs. Conditions of employment, and access to National Security Agency (NSA) automated information systems, requires that all employees and contractor personnel file an annual Security Financial Disclosure Form (SFDF), SF714, in accordance with Executive Order $12968{ }^{6}$ and stipulated in 50 U.S.C. 435. ${ }^{7}$ The detailed personal information required for SFDF includes bank and investment accounts, owned or leased real estate/vehicles/boats/airplanes, as well as credit card and mortgages payment and balances. ${ }^{8}$ This additional security monitoring, an institutional reaction implemented in SFDF, was initiated in 1995, just after Aldrich Ames’ 1994 espionage conviction. $^{9}$

NSA's institutional reaction to these recent releases of volumes of classified information will likely also be legalistic. Additional security monitoring actions, intending to prevent future releases, may not consider impacts on employees. This paper address the problem that employee morale, recruitment and retention may be damaged by public perception of NSA activities, as well as from additional security monitoring of employees. Increasing monitoring of employees 
effectively punishes current employees for the grave damage done by past employees who unlawfully released classified information.

Current practices to mitigate insider threats include Agency leaders' talking about core values ${ }^{10}$, an entry-on-duty oath, and annual mandatory training that emphasizes lifelong obligations. On their first day of employment, and not again at any later date, new employees take an oath and sign a lifelong obligation agreement to protect classified information. Mandatory annual training reinforces explanations of missions, information security processes and penalties as well as employees’ obligations, laws, and Executive Order authorizations.

The lifelong obligation to protect classified information entails a legalistic approach that primarily uses negative reinforcement means of threatened legal prosecution and punishment. For example, the NSA Office of General Counsel/Administrative Law and Ethics office explains ethics as the behavior underpinning compliance with law through Regulation 5CFR2635 2365.01 Federal Employees Standard of Conduct. While appropriate and necessary, this paper suggests that a legalistic approach is not sufficient in all cases. It does not create an esprit de corps to help employees work through ethical dilemmas regarding missions or capabilities. It does not foster resilience amongst employees given that protection of classified information imposes an often non-social organizational culture.

NSA culture, in keeping with E.O. 12698, practices “need to know” for access to classified information. Practices and processes are necessarily designed to isolate information and people, and intelligence professionals vet co-workers in most workplace interactions. All of these factors make an insider threat particularly damaging to the multi-faceted trust involved in intelligence work. Institutional responses to the grave damage from the 2010 and 2013 compromises of classified information may involve expanded employee monitoring. To improve 
trust, the author proposes new measures that focus on positive, instead of negative, reinforcement of expected behaviors of employees as intelligence professionals.

This paper proposes a new effort to create an ethos, through shared values, that builds workforce cohesion, enhances belief in mission, and strengthens employees’ resilience. Because self-identity is related to behavior, ${ }^{11}$ employees’ identifying themselves as intelligence professionals is likely to enhance compliance with professional norms as well as lifelong obligations. In contrast, absence of identity as professionals may consign individuals to greater risk of pursuing courses of action consistent with an alternative "good," which may instead bring long-lasting damage to the security of the United States. A newly-expressed NSA ethos will enable employees to reconcile dilemmas about their patriotic work in good faith. 


\section{Thesis}

This paper proposes a new Code of Ethics and Professional Conduct that describes shared values and expected behaviors for NSA Intelligence professionals. This Code will help employees work through and resolve ethical dilemmas when they feel that their job duties conflict with their conscience. It will enhance legal support provided by the Offices of General Counsel, Inspector General, and Compliance Office, by inculcating a new culture of mutual support. The Code will engender a professional esprit de corps and help further communicate NSA’s commitment to earning public trust, accountability, and lawfulness.

This paper will not address reasons for release of classified information for financial gain, foreign allegiance, or mental instability. Assistance is available through Employee Assistance Service as well as supervisors and leadership. Recent most-damaging releases of classified information by Edward Snowden has brought forth negative public debate about the National Security Agency’s activities, capabilities and operations. Public unease may affect employees’ personal perceptions and bring about ethical dilemmas about NSA's mission or capabilities. This paper proposes that a new NSA Code of Ethics and Professional Conduct will create an ethos to buoy morale, improve retention and help prevent future releases of classified information. 


\section{Shared Values}

Shared values help individuals form into a cohesive group. Values are defined in the Oxford American Dictionary as “a person’s principles or standards of behavior,” In the United States military, they tell individuals how to live every day and how to behave as members of their Service. They provide strength and enable perseverance through personal and group adversity, small and large challenges, and warfighting. Shared values express the personality of the group and remind its members of their ideals.

\section{U.S. Military Services' Values}

The U.S. military services describe values in ways that reflect their organizational cultures. Air Force core values of "integrity first, service before self and excellence in all we do" include detailed explanations for accountability. ${ }^{12}$ The Army's 7 practical, relevant values are each described with a few sentences that explain what a solider does to embody them. ${ }^{13}$ The Navy refers to its historical roots and lists expected behaviors for each value, i.e., "for honor...we will conduct ourselves in the highest ethical manner...” ${ }^{14}$ The Marine Corps defines each value in terms of how they are seen in each Marine, i.e., "courage ... is the inner strength that enables a Marine to take that extra step.” 15

In addition to values, Services’ creeds, songs, emblems and insignia are visible accounts of what it means to be Airmen, Soldiers, Sailors, Marines and Coast Guardsmen. The Army and Coast Guard also publish an Ethos that begin with the words "I am a Coast Guardsman. I serve the people of the United States...” ${ }^{16}$, and the Army's Warrior Ethos, "I will always place the

mission first.... ${ }^{17}$ Fittingly, organizations and agencies, are "autonomous social groups [that] can be partly defined by...their constitutive goals, values, beliefs, norms and standards...called 
the ethos of the group." 18 The modern public face of an organization, its website, is the visible display of this ethos.

\section{U.S. Intelligence Community Values}

Given that NSA is both a U.S. Department of Defense (DOD) and IC agency, let's compare its published values to DOD’s Defense Intelligence Agency (DIA) and the IC’s Central Intelligence Agency (CIA) values on their public websites. DIA's values list is succinct, and therefore, I submit, identifiable for its employees. DIA values of teamwork, integrity, excellence and service are each explained with a clause. ${ }^{19}$ CIA's core values of service, integrity and excellence are each expanded with 3 expected behaviors, i.e., for excellence, “we hold ourselves - and each other - to the highest standards.” 20

In contrast, NSA’s core values are not explicitly listed on its public website. The Commitment page extols promises of "integrity, transparency, accountability and respect for the law" to the United States, our fellow citizens, and the community. A supplemental brochure, entitled NSA/CSS Core Values/Clear Vision, focuses on operations, mission, compliance, heritage and future goals. In a video message from the most recent, former Deputy Director John C. Inglis, he discusses "respect for the law, honesty, integrity and transparency." ${ }^{21}$ Eight questions in a text version clarify NSA's respect for the law and transparency, but do not expand on the core values of personal honesty and integrity. The website also describes the relative importance of civil liberties and national security, compliance, legal rules, and the mission. Thus, the public face of NSA focuses outward on its mission and service to protect the nation, whereas this paper proposes articulating values as a new inward focus that explains to employees how we will behave and reminds us of our ideals. 
The Office of the Director of National Intelligence (ODNI) website lists three values, Stewardship, Excellence and Diversity in its Principles of Ethics for the Intelligence Community. It describes stewardship in terms of public trust, protecting sources and methods, reporting wrongdoing and remaining accountable “...ultimately to the American people.” Excellence means improving performance, "sharing information responsibly,” collaborating and innovating. And Diversity includes promoting "diversity and inclusion in our work force...” as well as in our thinking. These general principles of ethics apply across the U.S. Intelligence Community and thus NSA should articulate compatible values specific to its culture.

\section{Proposed Updated NSA Values}

NSA values correlate to those of ODNI, and support intelligent, creative and forwardthinking employees to stay ahead of adversaries and ensure the safety and security of our nation. To help employees work through possible dilemmas from mission work conflicts with their consciences, the author proposes explicitly defining shared values that represent ethical ideals.

For example, a succinct, yet relatable, values statements may be articulated as follows:

NSA employees strive to continuously improve performance and hold ourselves to the highest standards. We encourage adaptive and forward-thinking ideas to develop new approaches. We protect United States information and information technology. We partner with other federal agencies. We are dedicated to delivering for U.S. decision makers and service members alike. Thus, all dedicated NSAers are committed to three enduring values:

- Integrity: truthful words match our actions and we are accountable to the nation, community, managers and leaders, and fellow employees;

- Competence: we are dedicated and focused professionals who overcome technological challenges and excel in all intelligence-related skills;

- Patriotic Service: we trust and are loyal to the United States and its Constitution, the Intelligence Community and the Agency.

Shared values, such as those suggested above, will enhance employee cohesion and underpin a new inward focus on employees by articulating NSA values in a personal manner. 
Describing intelligence as a profession with associated professional ethics standards will further uplift employee morale and resilience.

\section{Professional Ethics}

\section{Professional Ethics Standards}

In the study of professional ethics, a central theme is that "competence is perhaps the most crucial characteristic" and is derived from a basic notion of trustworthiness or integrity. ${ }^{22}$ For example, in the law and medical professions, competence, which is crucial in order to become a member, is achieved from education as well as the number of cases tried or operations performed, and is followed by trust. If a lawyer or doctor is incompetent, we will not trust them to perform a job and they may lose their professional license. Intelligence is different in that trust is paramount, and while competence is important, it is considered after trust has been established.

In general, "competence is a character trait, a disposition to act in certain ways...” 23

Furthermore, "to have integrity is largely to have those qualities that render one trustworthy." ${ }^{24}$ Thus, I believe that both integrity and competence are top values in the intelligence field.

In the author's experience, NSA employees, like all professionals, are driven to excel in their work. Given the classified work environment, where need-to-know is the criteria to obtain access to classified information, employees must believe that a co-worker will do the work competently, after first establishing that they are trustworthy. Despite employees' holding security clearances, operational details and sources and methods are held to a strict need-to-know basis so that trustworthiness is continually earned through personal and operational experience.

Those who work in classified environments hold trustworthiness amongst fellow employees as paramount. Edward Snowden's extensive classified information releases and the 
associated loss of mission capabilities, tools and techniques places significant stress on the employee-to-employee trust that is vital for mission success. Changes to laws and national security policy necessarily adjust missions, but the insider threat, made real by Manning's and Snowden's releases, are disheartening and demoralizing to the employees whose patriotic service protects the nation. Such releases may especially damage the cohesion of the workforce.

\section{Team Cohesion and Self-esteem}

The Greek philosopher Aristotle’s examinations of ethics and ethical practices, when applied to the study of business ethics, puts forth that ethics are the nexus of the "individual, the corporation, and the community, self-interest and the public good.” ${ }^{25}$ Two aspects of this assertion accurately characterize NSA employees. Excellence is described as a "word of great significance and indicates a sense of mission...It is a word that suggests [not only] 'doing well' but also 'doing good.' " ${ }^{26}$ People are motivated to work at NSA, often for less pay than in a commercial industry job, to do good. Aristotle’s writings also capture the essence of community, applicable to the IC as well as NSA, "in which a sense of collective purpose and social wellbeing defines the aspirations and virtues of the individual.”27

A modern philosopher, John Rawls of Harvard University, describes the "social bases of self-respect” in his 1971 seminal book, A Theory of Justice. The social bases of self-respect are "those aspects of basic institutions normally essential if citizens are to have a lively sense of their

worth as persons...” ${ }^{28}$ While Rawls’ work discussed social bases as features of basic society, the IC, and thus NSA, from society-like organizational cultures.

\section{Benefits of Articulating Organizational Ethics}

Group norms characterize the broader IC, and its member agency NSA, whose culture is steeped in security protocols, protecting classified information, following the law, and being 
honest. Articulating values and professional ethics in the NSA culture will bring added focus to employees as individuals. A social contract will help all employees not only hold each other accountable, but also support each other to do the right thing, and thus may curb possible future breaches of classified information. Commencing a new dialogue about values, professional ethics and expected behaviors, will help boost employees' outlook about NSA's mission and their intelligence work.

\section{The Profession of Intelligence}

\section{Definitions of Intelligence}

A literature search reveals numerous definitions of Intelligence, illustrated in a 1990 dictionary of intelligence terms in which 17 pages contain 127 definitions. ${ }^{29}$ NSA was established by order of President Truman in 1952, and a declassified 1958 definition is still fitting today, "Intelligence is the collecting and processing of that information about foreign countries and their agents which is needed by a government for its foreign policy and for national security...” 30

More recently, in 1996, the Joint Military Intelligence College provided a description of Intelligence as: "knowledge of the enemy, and the operational environment, both of which are processed and packaged for a specific customer's requirements for making decisions in matters of national security and operational execution.” ${ }^{31}$ The JMIC author also proposed principles of Intelligence, based on his analysis of doctrine: accuracy, objectivity, usability, relevance, readiness (systems responsiveness) and timeliness. ${ }^{32}$ In this paper's author's experience, these definitions and descriptions of principles accurately capture the characteristics of the Intelligence field. 


\section{Definitions of Professions}

In order to assert that Intelligence is indeed a profession, this paper focuses on the body of work that encompasses Intelligence and its role in society. "The professions are characterized by three or four central features - extensive training, a significant intellectual component to practice, the provision of an important service, and perhaps credentialing." ${ }^{33}$ The missions and activities of NSA reflect extensive training and intellectual capital utilized in the diverse signals intelligence disciplines, including communications intelligence (COMINT), electronic intelligence (ELINT) and foreign instrumentation signals intelligence (FISINT). The important service aspect of those disciplines is reflected in ODNI's reference to the IC's role to protect the United States against transnational threats such as terrorism, proliferation, chemical and biological warfare, and information infrastructure.

Extensive training and specialized credentialing is required for most NSA positions. Newly-hired employees with undergraduate and graduate degrees learn the "SIGINT business" through on-the-job training as well as multi-year development programs and internships in engineering, mathematics, foreign language, intelligence analysis, etc. Intelligence training, analogous to credentialing, is a process of establishing extensive, specialized skills. SIGINT training and experience enables varied careers in computer science, mathematics, engineering, foreign languages, intelligence analysis, installation and logistics, and business and security.

In this paper the author argues that all work roles, including support functions such as security services, installation and logistics, and training, are essential components of NSA's intelligence mission. The requirement to learn the SIGINT business indicates a significant intellectual component to practicing Intelligence. Therefore, these support functions also 
encompass Intelligence work, as all mission areas require specialized training and knowledge to practice.

In addition, aspects of the role of professions further support that Intelligence is a profession - provision of services related to basic values, control or monopolization of the provision of services and membership in them, and self-regulation.” ${ }^{34}$ Intelligence provides services integral to the basic values of America, by providing critical information to the President, the National Security Council, Secretaries of Defense and State and other Executive Branch officials, to conduct foreign relations and protect national security. Control of services and membership is conducted through security clearance processes. Self-regulation is achieved via need-to-know practices and "out-of-the-box" thinking, within the bounds of law, to perform Intelligence work. "Intelligence professionals cannot afford to consider only information that conforms to their own pre-existing worldview or agreed upon, collective perspective.” 35

\section{Characteristics of Intelligence as a Profession}

Expanding on the 1947 definition, ODNI today describes Intelligence as “activities necessary for the conduct of foreign relations and the protection of the national security of the United States. [Further,] activities to protect against intelligence activities directed against the US, international terrorist and international narcotics activities, and other hostile activities directed against the U.S. by foreign powers, organizations, persons, and their agents.” 36

The Intelligence profession may be characterized by analogy to the medical profession, as “in medicine, success is measured post facto." ${ }^{37}$ Like medicine, where failures may only be evident when the patient dies, intelligence failures may only become evident when attacks occur or unforeseen events damage foreign relations situations. However, when intelligence is successful, when the patient lives, it is not known how well the profession performed. 
Lastly, other characteristics of professions that apply to the Intelligence profession include that: "they are voluntary [we must seek membership]; they are organizations; they have special, morally permissible standards for conducting business, and to be a member is to be subject to a special set of standards.” 38

\section{Recommendations}

U.S. Intelligence professionals were called upon to change focus from nation-states to violent non-state actors, after the end of the Cold War, and particularly after the Global War on Terror began, after the September 11th 2001 attacks. The 2006 Joint Chiefs of Staff National Military Strategic Plan for the War on Terrorism, asserts that "The United States is at war against extremists who advocate and use violence to gain control over others, and in doing so, threaten our way of life.” ${ }^{39}$ Preventing terrorist attacks entailed launching more proactive intelligence gathering and direct action operations, which have recently brought governmental transparency, individual privacy and civil liberties rights into public debate. Intelligence leaders must be aware of the effect that these debates have on the public as well as intelligence professionals.

"Professional ethics...involves aspects of the political, social, and legal philosophy as well.” 40

A new code of professional ethics will help NSA Intelligence practitioners to better cope with the pressures of carrying out missions against terrorist and other transnational threats in addition to long-standing SIGINT missions. A code of professional ethics may be leveraged as a mechanism of social contract, "a way of coordinating the conduct of people engaged in a common occupation." ${ }^{41}$ Furthermore, "adopting a realistic code is part of making an occupation [into] a distinct profession.” 42

The dedicated NSA workforce takes an unassuming role with an organizational culture that focuses on mission, law and compliance, commitments to protect our fellow citizens and 
nation, as well as NSA's role in the Department of Defense and the U.S. Intelligence Community. There is a special dichotomy that comes from doing the work of the National Security Agency: “They served in silence” is our way and "we won’t back down; we never have; we never will” has been a motto since the September $11^{\text {th }} 2001$ attacks. This paper proposes a new Code of Ethics and Professional Conduct to buoy the employees, and help them embody what it means to do this work. This code will bring an ethical culture to the forefront, improve morale and loyalty of all employees, and raise the level of confidence and trust with overseers as well as the public.

\section{Example Professional Codes of Ethics}

To draft a Professional Code of Ethics, this author reviewed examples that represented the attributes of Intelligence. Project management attributes are similar to good practices of Intelligence work performed at NSA. Timeliness, cost and resource savings, quality, efficiency, and productive communication with customers and stakeholders are practices that Project Management Institute (PMI) brings about through its accreditation community. Thus, PMI's

Code of Ethics and Professional Conduct, ${ }^{43}$ shown in Appendix A, is a good example to consider in developing an NSA Code of Ethics and Professional Conduct.

While PMI's Code of Ethics and Professional Conduct is clear, logical and thorough, its eight-page length would likely be cumbersome for NSA's time-critical, technologically and operationally-driven employees. In the author's experience, this mission-focused culture is most receptive to succinct, highly-relevant, relatable information that will help employees do their jobs.

NSA employees, who are often working on time-critical activities for incomplete and changing problems, will be most receptive to a one-page Code. Below is a proposed outline: 


\section{Proposed NSA Code of Ethics and Professional Conduct}

I. Vision \& Purpose:

a. This Code of Ethics and Professional Conduct sets the expectations that we have for ourselves as NSA Intelligence Professionals. It describes required behaviors as well as those to which we aspire.

b. It is in keeping with ODNI's Principles of Professional Ethics for the Intelligence Community: Stewardship, Excellence and Diversity.

c. This Code will shore up internal mechanisms for airing concerns. It will help NSA employees work through possible ethical dilemmas regarding missions or capabilities.

d. It will provide 'big picture' transparency. Articulating this code will improve buyin, group cohesion and camaraderie.

II. Persons to Whom Code Applies

a. This Code applies to all civilian employees, interns and military personnel of NSA.

III. Values that support Code

This Code is our commitment that our everyday behavior at work will reflect shared values of Integrity, Competence and Patriotic Service.

a. Integrity means that we uphold the highest standards. We always speak the truth. We commit to continually improving our skills and sharing our knowledge to increase our contributions to mission.

b. Competence means that we develop the related abilities, commitments, knowledge and skills to act effectively in any job or situation. ${ }^{44}$

c. Patriotic Service means that we are dedicated to the mission and are very responsive to customers' needs. We always act in accordance with U.S. laws.

IV. Aspirational and mandatory behaviors

a. Integrity: Aspirational behaviors

i. We will do what is best for the mission while taking care of our health and well-being.

ii. We will follow-through with commitments and always do what we say.

b. Integrity: Mandatory behaviors

i. We will speak and seek the truth in all workplace situations.

ii. We will solve problems and challenges in the correct way.

c. Competence: Aspirational behaviors

i. We will continually learn and broaden our skills.

ii. We will seek and perform higher level roles with broader mission impact.

d. Competence: Mandatory behaviors

i. We will perform each job to the best of our ability.

ii. We will seek information and actively learn skills needed to perform well. 
e. Patriotic Service: Aspirational behaviors

i. We will make decisions that are best for the U.S. and its taxpayers.

ii. We will embrace transparency to the fullest extent possible.

f. Patriotic Service Mandatory behaviors

i. We will always act in a lawful manner.

ii. We will always act in ways that earn the public trust.

\section{Proposed Implementation Means}

An NSA Code of Ethics and Professional Conduct provides a means for employees to verbalize values and standards that are present, but not necessarily explicitly communicated on a regular basis. Senior leadership must 'own' this Code and affirm it in order to develop a visibly ethical Agency environment, foster a more resilient workforce, and inspire public trust. Implementation goals include inculcating values and behavior standards into employees, managers and leaders throughout the Agency.

A communication plan enables senior leaders to convey and publicize the Code to all employees. ‘Bumper sticker’ and ‘elevator speech’ versions allow leaders to express it during all workforce wide events including Town Hall meetings, promotion ceremonies, etc. Presenting succinct versions when giving service anniversary pins and during development programs' graduations, etc. will further enable leaders to diffuse this Code throughout the NSA culture.

This new Code of Ethics and Professional Conduct should be presented and discussed at all new employee orientations and throughout all leadership training courses, analyst courses, etc. Additionally, training courses may be augmented to include case studies that involve ethical dilemmas, citing examples such as the Manning and Snowden situations. Example scenarios and means of discussing dilemmas may be obtained by consulting CIA training curricula. 


\section{Conclusion}

In this paper, the author describes military Services’ shared values and propose shared values of the NSA culture. Professional ethical standards and benefits of articulating organizational ethics are also discussed. The author defines professions as well as Intelligence, and argues that Intelligence is indeed a profession. She then proposes a new NSA Code of Ethics and Professional Conduct, and lastly, suggests implementation measures to inculcate values and behavior standards throughout the Agency. Implementing a new Code will help NSA employees to not only hold each other accountable, but also to support each other to continue to do "what's right.” It will help create an NSA ethos that enables employees to work through personal dilemmas about the mission or tools and thus help to thwart possible future releases of classified information.

The U.S. Intelligence Community performs its missions in compliance with U.S. law, according to Agencies' authorities, and accountable to U.S. Government oversight. Civilian personnel at NSA, on their first day of employment, take an oath and sign an agreement to protect classified information for life. Recurrent training at all levels reinforces the laws, penalties and obligations.

A new NSA Code of Ethics and Professional Conduct will enable organizational healing from the damage caused by recent releases of classified information and the ensuing public debate about Intelligence, security, citizens' privacy and public trust. Openly communicating our shared values and connecting those values to professional conduct will not only protect against a future insider threat by engaging in explicit dialogue but also increase workforce confidence and public trust. Changing an organization's culture is challenging, but fortifying the NSA workforce 
with this Code will reinforce additional security policies and bring dividends for employee morale, recruitment and retention. 


\section{Appendix}

The Project Management Institute (PMI) is a non-profit organization for that provides standards, conferences, publications, training and certification for project management professionals. Its certifications are the de facto standards worldwide, and in 2013 over 500,000 people held this certification. Its Project Management Book of Knowledge describes “good” project management practice, and PMI’s approach is process-oriented. “Good” project management practices provide benefits across business, government and industry.

PMI Code of Ethics and Professional Conduct has five chapters, each with a description as well as aspirational and mandatory standards of behavior. Mandatory standards include wording such as “we do not...” actions/behaviors. In addition, the first chapter, Vision and Applicability, describes the Codes’ vison and purpose “...to instill confidence in the project management profession and to help an individual become a better practitioner;” persons to whom the Code applies; structure [format]; values that support this Code...”responsibility, respect, fairness and honesty...” The second chapter, Responsibility, includes mandatory standards with regulations and legal requirements and ethics complaints sections. For example, in the Respect chapter mandatory standards are typically worded such as, “... we listen to others...we conduct ourselves in a professional manner...” The Fairness Chapter's mandatory standards include conflict of interest, favoritism and discrimination sections. In the fifth chapter, Honesty, aspirational standards include “we provide accurate information in a timely manner.” The Code’s Appendix include history of this standard and description of the process used to create it; Appendix B is a glossary. An outline of the version found on pmi.org website in December 2014 is as follows (see endnote 43):

PMI Code of Ethics and Professional Conduct

1. Vision and Applicability 
1.1. Vision and Purpose - “...to instill confidence in the project management profession and to help an individual become a better practitioner.”

1.2. Persons to Whom the Code Applies

1.3. Structure of the Code - "...divided into sections that contain standards..."

1.4. Values that Support this Code - “...responsibility, respect, fairness and honesty"

1.5. Aspirational and Mandatory Conduct

2. Responsibility

2.1. Description - “...is our duty to take ownership of the decisions we make or fail to make...”

2.2. Responsibility Aspirational Standards

2.3. Responsibility Mandatory Standards - "Regulations and Legal Requirements”; "Ethics Complaints”

3. Respect

3.1 Description - "our duty to show a high regard for ourselves, others and the resources entrusted to us..."

3.2 Respect Aspirational Standards

3.3 Respect Mandatory Standards

4. Fairness

4.1 Description - "to make decisions and act impartially and objectively..."

4.2 Fairness Aspirational Standards

4.3 Fairness Mandatory Standards - “Conflict of Interest Situations”; "Favoritism and Discrimination"

5. Honesty

5.1 Description - "duty to understand the truth and act in a truthful manner..."

5.2 Honesty Aspirational Standards

5.3 Honesty Mandatory Standards

Appendix A

A.1 History of This Standard

A.2 Process Used to Create This Standard

Appendix B

B.1 Glossary 


\section{Notes}

${ }^{1}$ Ian Simpson and Medina Roshan, "U.S. soldier Manning gets 35 years for passing documents to WikiLeaks," August 21, 2013 5:02PM, Reuters, http://www.reuters.com/article/2013/08/21/us-usa-wikileaks-manning-idUSBRE97J0JI20130821 (accessed 13 February 2015)

${ }^{2}$ R.C. Porter, Fortuna's Corner, Blog at WorldPress.com, "Congress Tells DOD To Report on Leaks, Insider Threats,” Secrecy News, Volume 2014, Issue No. 82, December 8, 2014, http://fortunascorner.com/2014/12/08/congress-tells-dod-to-report-on-leaks-insider-threats/

${ }^{3}$ Ibid.

${ }^{4}$ National Archives, Federal Register, Codification, Executive Orders, Executive Order 12333-United States Intelligence Activities, "Source: The provisions of Executive Order 12333 of Dec. 4, 1981, appear at 46 FR 59941, 3 CFR, 1981 Comp., p. 200, unless otherwise noted", http://www.archives.gov/federal-register/codification/executive-order/12333.html (accessed 1 February 2015)

${ }^{5}$ Office of the Federal Register, Presidential Documents, Access to Classified Information: A Presidential Document by the Executive Order of the President on 08/07/1995, https://www.federalregister.gov/articles/1995/08/07/95-19654/access-to-classified-information (accessed 10 December 2014)

${ }^{6}$ National Security Agency, "Statement of Conditions of Employment," Form P2771 Rev June 2009, https://www.nsa.gov/careers/_files/P2771.pdf (accessed 10 December 2014)

${ }^{7}$ U.S. Government Publishing Office, FDsys/More information, 50 U.S.C 435B - Security Clearances, http://www.gpo.gov/fdsys/granule/USCODE-2009-title50/USCODE-2009-title50chap15-subchapVI-sec435b (accessed 10 February 2015)

${ }^{8}$ U.S. General Services Administration, GSA Forms Library Find a Form, Form SF714 Rev 01/2009, "Financial Disclosure Report," http://www.gsa.gov/portal/forms/download/116750 (accessed 10 December 2014)

${ }^{9}$ The FBI Federal Bureau of Investigation, "Famous Cases \& Criminals, Aldrich Hazen Ames,” http://www.fbi.gov/about-us/history/famous-cases/aldrich-hazen-ames, (accessed 10 February 2015)

${ }^{10}$ National Security Agency, "Mission, Vision, Values," https://www.nsa.gov/about/values/index.shtml (accessed 11 December 2014)

${ }^{11}$ Martin Fishbein and Icek Azjen, Predicting and Changing Behavior: The Reasoned Action Approach, (New York: Psychology Press, 2010), 290.

${ }^{12}$ U.S. Air Force, “Our Values,” http://www.airforce.com/learn-about/our-values/ (accessed 12 December 2014)

${ }^{13}$ U.S. Army, “The Army Values,” http://www.army.mil/values/ (accessed 12 December 2014) 
${ }^{14}$ U.S. Navy, "Honor, Courage, Commitment: The United States Navy,” http://www.navy.mil/navydata/nav_legacy.asp?id=193 (accessed 12 December 2014)

${ }^{15}$ U.S. Marine Corps, "What are the Marine Corps Values?”

http://www.hqmc.marines.mil/hrom/NewEmployees/AbouttheMarineCorps/Values.aspx (accessed 12 December 2014)

${ }^{16}$ United States Coast Guard, "United States Coast Guard Ethos,” http://www.uscg.mil/top/about/doc/Coast_Guard_Ethos.pdf (accessed 30 January 2015)

${ }^{17}$ United States Army, “Army Values, Warrior Ethos,” http://www.army.mil/values/warrior.html (accessed 9 February 2015)

${ }^{18}$ Raimo Tuomela, The Philosophy of Sociality: The Shared Point of View (New York: Oxford University Press, 2007), 44.

${ }^{19}$ Defense Intelligence Agency, “About DIA,” http://www.dia.mil/About.aspx (accessed 12 December 2014)

${ }^{20}$ Central Intelligence Agency, "CIA Vision, Mission \& Values,” https://www.cia.gov/mobile/about-cia/cia-vision-mission-values.html (accessed 12 December 2014)

${ }^{21}$ National Security Agency, "NSA/CSS Core Values with NSA's Deputy Director Chris Inglis,” https://www.nsa.gov/about/values/core_values.shtml (accessed 12 December 2014)

${ }^{22}$ Michael D. Bayles, Professional Ethics (California: Wadsworth Publishing, 1982), 75

23 Ibid., 22.

${ }^{24}$ Karen Lebacqz, Professional Ethics: Power and Paradox (Nashville TN: Abingdon Press, 1985), 88. 145.

${ }^{25}$ Robert C. Solomon, Ethics and Excellence (New York: Oxford University Press, 1992),

26 Ibid., 153.

27 Ibid., 161.

${ }^{28}$ Quoted in Thomas E. Hill, Jr., "Stability, a Sense of Justice and Self-Respect”, in $a$ Companion to Rawls: Blackwell Companions to Philosophy, ed. Jon Mandle et. al. (Malden, MA, John Wiley \& Sons, 2013), 206.

${ }^{29}$ Quoted in William S. Brei, “ Getting Intelligence Right: The Power of Logical Procedure (excerpt)”, originally published as Occasional Paper Two, 1996, Joint Military Intelligence College, Learning with Professionals: Selected Works from the Joint Military Intelligence College 50.

${ }^{30}$ Michael Warner, Wanted: A Definition of 'intelligence', ed. Christopher Andrew, Richard J. Aldrich, Wesley K. Wark, Secret Intelligence: A Reader (New York: Routledge, 2009), 8

${ }^{31}$ Brei, “Getting Intelligence Right,” 50.

32 Ibid., 51. 
${ }^{33}$ Michael D. Bayles, Professional Ethics (Belmont, California: Wadsworth Publishing, 1989), 14.

34 Ibid., 14.

${ }^{35}$ David T. Moore, Sensemaking: A Structure for an Intelligence Revolution (Washington, DC: National Intelligence University, July 2012), 12.

${ }^{36}$ Office of the Director of National Intelligence, “ODNI FAQ,” http://www.dni.gov/index.php/about/faq?start=2 (accessed 14 December 2014)

${ }^{37}$ Moore, Sensemaking, 95.

${ }^{38}$ Michael Davis, Thinking Like an Engineer: Studies in the Ethics of a Profession, (New York: Oxford University Press, 1998), 164-165.

${ }^{39}$ United States Department of Defense, Chairman of the Joint Chiefs of Staff, National Military Strategic Plan for the War on Terrorism, (Washington, DC, February 2006), 3.

${ }^{40}$ Michael D. Bayles, Professional Ethics, (California: Wadsworth Publishing, 1989), 3.

${ }^{41}$ Ibid., 3.

42 Davis, Thinking Like an Engineer, 112-113.

${ }^{43}$ Project Management Institute, "Code of Ethics and Professional Conduct," http://www.pmi.org/ /media/PDF/Ethics/ap_pmicodeofethics.ashx (accessed 13 December 2014)

${ }^{44}$ WebFinance, Inc., Business Dictionary.com, http://www.businessdictionary.com/definition/competence.html (accessed 30 January 2015) 


\section{Bibliography}

Bayles, Michael D. 1989. Professional Ethics. Belmont CA: Wadsworth Publishing Company.

Bayles, Michael D. 1982. Professional Ethics. Belmont, CA: Wadsworth Publishing Company.

Brei, William S. 1996. "Getting Intelligence Right: The Power of Logical Procedure." Joint Military Intelligence College Occasional Paper Two (Joint Military Intelligence College).

Central Intelligence Agency. n.d. CIA Vision, Mission \& Values. Accessed December 12, 2014. https://www.cia.gov/mobile/about-cia/cia-vision-mission-values.html.

Chairman of the Joint Chiefs of Staff. 2006. National Military Strategic Plan for the War on Terrorism. Washington DC: Department of Defense, 38.

http://www.defense.gov/pubs/pdfs/2006-01-25-Strategic-Plan.pdf.

Davis, Michael. 1998. Thinking Like An Engineer: Studies in the Ethics of a Profession. New York: Oxford University Press.

Defense Intelligence Agency. n.d. About DIA. Accessed December 12, 2014. http://www.dia.mil/About.aspx.

Federal Bureau of Investigation. n.d. "Famous Cases \& Criminals, Aldrich Hazen Ames." FBI About Us History Famous Cases. Accessed February 10, 2015. http://www.fbi.gov/aboutus/history/famous-cases/aldrich-hazen-ames.

Fishbein, Martin, and Icek Azjen. 2010. Predicting and Changing Behavior: The Reasoned Action Approach. New York: Psychology Press.

Hill, Thomas E. 2014. Stabilty, a Sense of Justice and Self-Respect. Edited by Jon Mandle and David A. Reidy. Malden , MA: John Wiley \& Sons.

Lebacqz, Karen. 1985. Professional Ethics: Power and Paradox. Nashville, TN: Abingdon Press.

Moore, David T. 2012. Sensemaking: A Structure for an Intelligence Revolution. Washington DC: Government Printing Office.

National Security Agency. 2009. "Statement of Conditions of Employment-Applicants." NSA Careers. June. Accessed December 10, 2014. https://www.nsa.gov/careers/_files/P2771.pdf.

National Security Agency/Central Security Service. 2009. National Security Agency Core Values with NSA's Deputy Director Chris Inglis. January 15. Accessed December 12, 2014. https://www.nsa.gov/about/values/core_values.shtml.

—. 2013. NSA Mission, Vision, Values. January 10. Accessed December 11, 2014. https://www.nsa.gov/about/values/index.shtml.

Office of the Director of National Intelligence. n.d. "ODNI FAQ." Office of the Director of National Intelligence: About ODNI. Accessed Deccember 14, 2014.

http://www.dni.gov/index.php/about/faq?start=2. 
Porter, R.C. 2014. "Secrecy News: 12/08/14 "Congress Tells DOD to Report on Leaks, Insider Threats"." R.C. Porter, Fortuna's Corner Blog. WorldPress.com. December 8. Accessed December 10, 2014. http://fortunascorner.com/2014/12/08/congress-tells-dod-to-report-onleaks-insider-threats/.

President Bill Clinton. 1995. "Access to Classified Information: A Presidential Document by the Executive Order of the President on 08/07/1995." Federal Register: The Daily Journal of the United States Government. August 7. Accessed December 10, 2014.

https://www.federalregister.gov/articles/1995/08/07/95-19654/access-to-classifiedinformation.

President Ronald Reagan. 1981. "Exectuive Order 12333--United States Intelligence Actvities." National Archives, Federal Register, Codification. December 4. Accessed February 1, 2015. http://www.archives.gov/federal-register/codification/executive-order/12333.html .

Project Management Institute. n.d. "PMI Code of Ethics and Professional Conduct." PMI Project Management Institute. Accessed December 13, 2014. http://www.pmi.org/ /media/PDF/Ethics/ap_pmicodeofethics.ashx.

Roshan, Ian Simpson and Meidna. 2013. U.S. soldier Manning gets 35 years for passing documents to WikiLeaks. A.

Simpson Ian, and Medina Roshan . 2013. U.S. soldier Manning gets 35 years for passing documents to WikiLeaks. Fort Meade Maryland, August 21.

Solomon, Robert C. 1992. Ethics and Excellence: Cooperation and Integrity in Business. New York: Oxford University Press.

Staff, U.S. Chairman of the Joint Chiefs of. 2006. "National Military Strategic Plan for War on Terrorism." February. Accessed December 14, 2014.

Tuomela, Raimo. 2007. The Philosophy of Sociality: The Shared Point of View. New York: Oxford University Press.

U.S. Air Force. 2014. "Our Values." U.S. Air Force. Accessed December 12, 2014. http://www.airforce.com/learn-about/our-values/ .

U.S. Army. n.d. "The Army Values." Army Values. Accessed December 12, 2014. http://www.army.mil/values/.

—. n.d. "Warrior Ethos." Army Values. Accessed February 9, 2015. http://www.army.mil/values/warrior.html.

U.S. Coast Guard. n.d. "United States Coast Guard Ethos." U.S. Coast Guard Homeland Security. Accessed January 30, 2015. http://www.uscg.mil/top/about/doc/Coast_Guard_Ethos.pdf.

U.S. General Services Administration. 2009. "Form SF714 Rev 01/2009." GSA Forms Library Find a Form. January. Accessed December 10, 2014. http://www.gsa.gov/portal/forms/download/116750.

U.S. Government Publishing Office. 2010. "50 U.S.C. 435B-Security Clearances." U.S. Government Publishing Office Search Government Publications. February 1. Accessed 
February 10, 2015. http://www.gpo.gov/fdsys/granule/USCODE-2009-title50/USCODE2009-title50-chap15-subchapVI-sec435b.

U.S. Marine Corps. n.d. "Marines Human Resources and Organizational Management ." New Employees About the Marine Corps Values. Accessed December 12, 2014. http://www.hqmc.marines.mil/hrom/NewEmployees/AbouttheMarineCorps/Values.aspx.

U.S. Navy. 2009. "Honor, Courage, Commitment: The United States Navy." America's Navy. August 12. Accessed Deccember 12, 2014.

http://www.navy.mil/navydata/nav_legacy.asp?id=193.

Warner, Michael. 2009. Wanted: A Definition of "intelligence". Edited by Christopher Andrew, Richard J Aldrich and Wesley K Wark. Vol. Secret Intelligence: A Reader. New York: Routledge.

WebFinance, Inc. n.d. Definitions. Accessed January 30, 2015.

http://www.businessdictionary.com/definition/competence.html. 
